Conclusion: In an unselected cohort of SSc patients, a third of the patients has ILD at baseline which is in line with previous prevalence reports. Importantly, this is the first study reporting incidence rates of SSc-ILD.

References:

[1] Steen VD and Medsger TA, Ann Rheum Dis 2007;66:940-4

[2] Elhai M et al. Ann Rheum Dis 2017;76:1897-1905

[3] Smith Vetal.RMD Open 2019;4:e000782. doi:10.1136/rmdopen-2018-000782

[4] Bergamasco A et al. Clinical Epidemiology 2019;11:257-73

[5] Goh N et al. Am J Respir Crit Care Med 2008;177:1248-54

[6] van den Hoogen et al. Arthritis Rheumatol 2013;65:2737-47

Disclosure of Interests: Els Vandecasteele Grant/research support from: my institution has received a research grant from the Research Foundation Flanders FWO), Speakers bureau: my institution has received speaker fees from Actelion, Karin Melsens: None declared, Daniel Blockmans Consultant of: yes, Speakers bureau: yes, Charlotte Carton: None declared, Filip De Keyser: None declared, Ellen De Langhe Consultant of: member of advisory board for Boehringer, Bernard Lauwerys: None declared, Yves Piette: None declared, Amber Vanhaecke: None declared, Koen Verbeke: None declared, Wim Wuyts Grant/research support from: my institution has received a grant from Boehringer Ingelheim and Roche, Consultant of: my institution has received payments for consultancy from Boehringer Ingelheim and Roche, Speakers bureau: my institution has received speaker fees from Boehringer Ingelheim and Roche, Guy Brusselle: None declared, Vanessa Smith Grant/research support from: The affiliated company received grants from Research Foundation - Flanders (FWO), Belgian Fund for Scientific Research in Rheumatic diseases (FWRO), Boehringer Ingelheim Pharma GmbH \& Co and Janssen-Cilag NV, Consultant of: Boehringer-Ingelheim Pharma GmbH \& Co, Speakers bureau: Actelion Pharmaceuticals Ltd, Boehringer-Ingelheim Pharma GmbH \& Co and UCB Biopharma Sprl

DOI: 10.1136/annrheumdis-2020-eular.1182

\section{THU0368 RAPID SKIN THICKNESS PROGRESSION RATE IS ASSOCIATED WITH HIGH INCIDENCE RATE OF CARDIOPULMONARY INVOLVEMENT AND MORTALITY IN PATIENTS WITH EARLY DIFFUSE CUTANEOUS SYSTEMIC SCLEROSIS (DCSSC)}

S. Wangkaew ${ }^{1}$, H. Thongwitokomarn ${ }^{1}$, N. Prasertwittayakii ${ }^{2}$, J. Euathrongchit ${ }^{3}$. ${ }^{1}$ Division of Rheumatology, Chiang Mai University, Internal Medicine, Chaing Mai, Thailand; ${ }^{2}$ Division of Cardiology, Chiang Mai University, Internal Medicine, Chaing Mai, Thailand; ${ }^{3}$ Division of Diagnostic Radiology, Chiang Mai University, Internal Medicine, Chaing Mai, Thailand

Background: There has been no prior inception cohort study regarding the incidence rate of cardiopulmonary involvement in patients with early dcSSc comparing among different groups of skin thickness progression rate.

Objectives: The aims of this study were to compare differences in early dcSSc patients, which were classified into 3 subgroups; (a) rapid skin progression [RPsp], (b) intermediate skin progression [IMsp], and (c) slow skin progression [SLsp]; regarding: (1) clinical characteristics,(2) incidence rate of left ventricular ejection fraction (LVEF) $<50 \%$, interstitial lung disease (ILD), and pulmonary hypertension $(\mathrm{PH})$. In addition, to compare mortality rate between skin improved and non-improved skin group.

Methods: We used an inception cohort of early dcSSc patients seen at the Rheumatology clinic, Maharaj Nakorn Chiang Mai Hospital, between January 2010 and December 2017. All patients were assessed for demographic data, clinical manifestations, modified Rodnan Skin Score (mRSS) and underwent echocardiography, and HRCT at the study entry and then annually.

Results: One hundred and two dcSSc patients (55 females and 89 anti-Scl 70 antibody positivity) with a mean \pm SD age of $53.2 \pm 8.8$ years and mean disease duration of $11.2 \pm 8.7$ months were enrolled, during a mean observation period of $54.0 \pm 24.0$ months. Mean \pm SD of baseline mRSS was $21.9 \pm 9.1$. Patients were classified into 3 groups: (a) 41 (40.2 \%) patients with RPsp; (b) 37 (36.3 \%) IMsp and; (c) 24 (23.5\%) SLsp. At enrollment, the RPsp group had significantly differences in clinical manifestations compared to IMSp and SLsp group as the followings: mean disease duration $(5.4 \pm 2.3$ vs. $11.5 \pm 6.1$ and $20.7 \pm 10.3$ months, $p<0.001)$, anti-Scl 70 antibody- positive ( $95.1 \%$ vs. $75.7 \%$ and $91.7 \%$, $p=0.035)$, mRSS $(26.4 \pm 7.9$ vs. $22.1 \pm 8.4$ and $13.8 \pm 6.5, p<0.001)$, dry mouth ( $48.8 \%$ vs. $37.8 \%$ and $8.3 \%, p=0.005)$, LVEF $<50 \%(26.8 \%$ vs. $21.6 \%$ and $0, p=0.010$ ), pericardial effusion ( 0 vs. $10.8 \%$ and $0, p=0.018$ ), arrhythmia ( 7.3 $\%$ vs. $29.7 \%$ and $8.3 \%, p=0.018)$, muscle weakness $(26.8 \%$ vs. $27.0 \%$ and $0, p=0.009)$, creatine kinase $\geq 500 \mathrm{U} / \mathrm{L}(34.1 \%$ vs. $18.9 \%$ and $4.2 \%, p=0.016$, and NT-proBNP $(935.7 \pm 2300.3$ vs. $746.4 \pm 1385.2$ and $164.0 \pm 225.3 \mathrm{ng} / \mathrm{L}, \mathrm{p}=$ $0.001)$. During the observation period, the RPsp group had a significantly higher incidence rate of LVEF $<50 \%$ compared with the SLsp group (6.06 vs. 0 per 100 person-years, incidence rate ratio $=21.27, p=0.001$ ). The RPsp group had a significantly higher incidence of ILD compared with the SLsp group (69.69 vs. 34.66 per 100 person-years, incidence rate ratio $=2.01, p=0.012$ ). Skin non-improved group had higher mortality rate compared with the skin improved group (28.6\% vs. $5.9 \%, p=0.004)$.

Conclusion: Our study cohort found that early dcSSc patients with rapid skin progression had higher incidence rate of LVEF $<50 \%$ and ILD compared to those with slow skin progression. In addition, skin non-improved patients had significantly higher mortality rates than those with skin improved.

Disclosure of Interests: None declared

DOI: 10.1136/annrheumdis-2020-eular.634

\begin{tabular}{|l}
\hline THU0369 \\
EVALUATION OF DIFFERENT CLASSIFICATION \\
CRITERIA IN SYSTEMIC SCLEROSIS IN A \\
TURKISH COHORT: THE IMPORTANCE OF \\
NON-SKIN MANIFESTATIONS, SEROLOGY AND \\
CAPILLAROSCOPY
\end{tabular}

Y. Yalçınkaya ${ }^{1}$, S. Amikishiyev ${ }^{1}$, N. Aliyeva ${ }^{1}$, B. Artim-Esen ${ }^{1}$, A. Gul ${ }^{1}$, L. Ocal ${ }^{1}$, M. Inanc ${ }^{1}{ }^{1}$ Istanbul University, Istanbul Medical Faculty, Department of Internal Medicine, Division of Rheumatology, Istanbul, Turkey

Background: Proximal scleroderma is the major criterion in both 1980 and 2013 classification criteria for sytemic scleroris (SSc). ACR(1980) criteria included digital lesions and bibasiler fibrozis, nonetheless ACR/EULAR(2013) criteria based on a scoring system including digital lesions, telangiectasia, abnormal nailfold video-capillaroscopy(NVC), PAH, Raynaud's and specific autoantibodies.

Objectives: We aimed to implement both criteria in a Turkish SSc kohort to evaluate the contribution of non-skin manifestations, NVC and autoantibodies.

Methods: A consecutive hundred and thirty-nine (125 females) SSc patients diagnosed and evaluated by the same experts (YY, MI) with relevant NVC records and at least 6 months follow-up were included into the study. Classificaiton criteria were used retrospectively using a preformed database.

Results: Characteristics of the SSc patients were summarized in table-1. The mean age, duration of Raynaud's and non-Raynaud symptoms were $47.1 \pm 11.9, \quad 8.9 \pm 7.9$ and $5.7 \pm 5.8$ years, respectively. Diffuse and limited cutaneous disease were diagnosed in $62(44.6 \%)$ and $60(43.2 \%)$ patients respectively. Asclerodermic disease was present in $17(12.2 \%)$ patients. ANA, anti-centromere and anti-Scl70(+) positivity was $80.5 \%, 18.0 \%$ and $37.4 \%$, respectively.

Twelve patients $(8.6 \%)$ could not be classified as SSc by both criteria; 5 with Raynaud's+specific antibodies (2 anti-centromere+, 2 anti-Scl70+), 4 with Raynaud's+puffy hands+NC abnormalities, 2 with Raynaud's+telangiectasia and a patient with Raynaud's+sclerodactyly. Nineteen (13.7\%) patients could not be classified as SSc according to ACR (1980) can be classsified according to ACR/ EULAR (2013) (table-1 and -2).

The sensitivity for ACR/EULAR (2013) and ACR (1980) criteria were found to be $91,4 \%$ vs $75,5 \% ; 98.4 \%$ vs $96.8 \%$ in diffuse cutaneous SSc, $98.3 \%$ vs $68.3 \%$ in limited cutaneous SSc and 47.1 vs $23.5 \%$ in asclerodermic SSc, respectively.

Table 1. The sensitivity for ACR (1980) and ACR/EULAR (2013) classification criteriain SSc

\begin{tabular}{lccr}
\hline & ACR/EULAR (2013) + & ACR/EULAR (2013) & total \\
\hline ACR (1980)+ & 108 & 0 & 108 \\
ACR (1980)- & 19 & 12 & 31 \\
total & 127 & 12 & 139 \\
\hline
\end{tabular}

Table 2. SSc patients fulfilling ACR (1980) and/or ACR/EULAR (2013) criteria

\begin{tabular}{lcc}
\hline ACR/EULAR (2013) ACR (1980) & Classified $\mathbf{n = 1 2 7}$ & Not classified $\mathbf{n = 1 2}$ \\
\hline +Prox scleroderma + & 87 & \\
+Puffy hands & 29 & 4 \\
+Sclerodactyly + & 112 & 1 \\
+Digital ulcers + +Pitting scars & 6272 & 2 \\
+Telangiectasia & 86 & 4 \\
+Nailfold capillaroscopy & 97 & 3 \\
$\quad$ Normal & 9 & \\
Early & 17 & 1 \\
Active & 40 & \\
Late & 50 & 12 \\
+PAH & 12 & 5 \\
+Interstitial lung Disease + & 60 & \\
+Raynaud's & 120 & \\
+SSc- specific antibodies & 79 & \\
\hline
\end{tabular}

Conclusion: The sensitivity of ACR/EULAR (2013) criteria was shown to be higher than ACR (1980) criteria in our Turkish SSc cohort with established cases. 